\title{
Dismantling the 'All-Boys Club' A Narrative of Contradictions Women Experience in PhD Mathematics Programs: A Freirean Approach
}

\author{
Weverton Ataide Pinheiro ${ }^{1 *}$ (D) \\ ${ }^{1}$ Indiana University Bloomington, USA \\ *Corresponding Author: wpinheir@iu.edu \\ Citation: Ataide Pinheiro, W. (2021). Dismantling the 'All-Boys Club' A Narrative of Contradictions Women Experience in PhD Mathematics \\ Programs: A Freirean Approach. International Electronic Journal of Mathematics Education, 16(3), em0652. https://doi.org/10.29333/iejme/11090

\begin{tabular}{|c|c|}
\hline ARTICLE INFO & ABSTRACT \\
\hline Received: 15 Jan. 2021 & Gender issues in mathematics education received fairly attention several decades ago, mainly because women \\
\hline Accepted: 9 Jun. 2021 & $\begin{array}{l}\text { and men performed differently, with men usually outperforming women. The research on such phenomena } \\
\text { originated a series of studies on the so-called 'achievement-gap.' After many years of research on the achievement } \\
\text { gap, such a gap has shown to have disappeared. However, recent studies have shown that there are fewer women } \\
\text { who choose STEM-related fields than male peers. Suppose women are not choosing mathematics, but } \\
\text { concomitantly research has pointed out that women and men have similar mathematics capabilities; why are } \\
\text { women disproportionately part of the field? Since current statistics show that } 90-95 \% \text { of doctoral mathematics } \\
\text { students are men, this study examines why school mathematics is still a male-dominant field. The data presented } \\
\text { in this paper was collected using life-story interviews. Freirean methodology was used to analyze the } \\
\text { contradictions in women's PhD student experiences. The findings point to contradictions in women's experiences } \\
\text { in mathematics regarding success and challenges women have faced in mathematics and are discussed in depth } \\
\text { in the findings and discussion sections of this paper. }\end{array}$ \\
\hline
\end{tabular}

Keywords: women in mathematics, gender and mathematics, mathematics education, contradictions

\section{INTRODUCTION}

Women's lack of representation in post-high school mathematics is still a topic discussed in many researchers' work in the $21^{\text {st }}$ century (e.g., Herzig, 2004; Leyva, 2017; Lubienski \& Ataide Pinheiro, 2020; Lubienski \& Ganley, 2017; Mendick, 2005b; Rubel \& Ehrenfeld, 2020). A handful of research has investigated women's experiences, taking into consideration different methods and methodological approaches. These research projects investigated different variables that might play a role in determining how women perceive, experience, and progress in mathematical spaces (Braathe \& Solomon, 2015; Good, Rattan, \& Dweck, 2012; Chronaki \& Pechtelidis, 2012; Herzig, 2004). Mendick (2003, 2005a, 2005b, 2006) and Solomon (2012) found that mathematics is a masculine arena where women's participation requires them to do masculinities (using competitive or rational behavior). Consequently, women in mathematics go through alienation (Ahlqvist, London, \& Rosenthal, 2013; Boaler, 2000), isolation (Herzig, 2004; Johnson, 2011), invisibility (Gholson, 2016), a sense of not belonging (Herzig, 2010; Solomon, 2007), and also the feeling of being special (Hall \& Suurtamm, 2018). Hyde, Fennema, and Lamon (1990) discussed how differences in gendered mathematics performances operate towards one's capability in mathematics. Renold and Allan (2006) and Solomon, Radovic, and Black (2016) talked about ways women saw possibilities to be feminine (use cultural tools such as skirt and heals to represent femininities) alongside mathematics. Although there were a multitude of contributing factors noted, within all these studies, one variable remains constant: underrepresentation. Women are more underrepresented as they progress in mathematics with very few women becoming research mathematicians (Cimpian et al., 2016; Lubienski et al., 2013). However, underrepresentation needs to be seen as a consequence of mathematics being exclusionary to women (Yeh \& Rubel, 2020); this could be a cyclical process with mathematics being exclusionary to women contributing to underrepresentation of women in the field.

To succeed in mathematics and stay in mathematical careers, women need to overcome a series of oppressive obstacles (Mendick, 2005a; Steele et al., 2007), obstacles that are exacerbated because of the relatively recent (historically speaking) access women have had to education and mathematics. These obstacles are understood in their essence by the analysis of the unit of struggles in women's experience, defined in this paper as contradictions. Women survival in the field of mathematics seems to be conditional on many negotiations that men do not need to go through. Freire's Pedagogy (1970/2017) provides lenses for understanding the lives of people conditioned by oppression and a methodological way to engage the oppressed in the process of conscientização (political awareness). Oppression is a dialectical relation between a pair of opposites, the oppressed and the oppressor. Therefore, in the current societal setup, the binary view of the sexes still plays a significant role in determining women's 
and men's experiences during their school years and in the workforce. In addition, due to inequities in the field of mathematics, this study builds on the academic consensus that women must work harder to establish and pursue freedoms in mathematical spaces.

The findings of the studies cited above lead this current study to assume that women experience forms of oppression as part of their participation in mathematical spaces, and that these experiences need to be foregrounded, analyzed, and discussed. This study intends to reconstruct how these oppressions are formed, continued, and perpetuated through an examination of contradictions in women's stories about pursuing a PhD in mathematics. This problem is not new, but rather, has occurred throughout at least the last four millennia (Stedall, 2012) in one of the oldest of the sciences (Man-Keung, 2000). Also, this research reiterates views of gender and how it informs the work presented here. I use Freire's theory to provide an analysis of the ways in which women experience oppression in mathematical spaces. This paper uses the term mathematical spaces, as defined by Walker (2012), as 'sites where mathematics knowledge is developed, where induction into a particular community of mathematics doers occurs, and where relationships or interactions contribute to the development of a mathematics identity' (p. 67). In particular, this study's research question is: What is the nature of contradictions that women who are pursuing a PhD in mathematics experience in mathematical spaces and mathematics?

\section{LITERATURE REVIEW}

\section{Gender Studies}

In mathematics education research, gender has been long undertheorized and conflated with ideas of sex (Damarin \& Erchick, 2010; Esmonde, 2011), mostly described as a synonym for one another. However, studies on gender and the intersectionality between mathematics education and gender studies have funneled down to a better understanding and definition of gender. This current study considers gender to be socially constructed, fluid, and have performative discursive characteristics, whereas sex is a fixed biological category (Butler, 1990, 2004). Because of the predominantly common categories of sex, male and female, gender mostly in our societies is translated into woman and man.

As much as it is hard to define 'women,' since women from different cultures, countries, races, and SES go through very different experiences that shape what and who they are (Mohanty, 1988), in this study, the word woman/women is used with the understanding that woman is a social and historical being with experiences that translate into narratives that cannot be essentialized (Rudrappa, 2015). However, to present and discuss the findings, the word woman/women is used. Intentionally, this study uses strategic essentialism, which is 'the process of deliberately categorizing people based on socially defined traits for the purpose of reaching higher (equity) goals' (Gutierrez, 2002, p. 154).

\section{Women and Mathematics}

In the past two decades, mathematics educators, psychologists, sociologists, and anthropologists have researched women's experiences in mathematical spaces. A group of studies, mostly quantitative, were relevant to inform how mathematical spaces have been shaped and who has taken 'the most out of mathematics' (Fennema et al., 1998; Fennema \& Sherman, 1977). The significant contribution of those studies is the finding that the so-called gender gap ${ }^{1}$ has almost disappeared between boys and girls in K-12 mathematics (Cimpian et al., 2016). If the gender gap has almost disappeared or is no longer statistically significant, it may be the case mathematics is a discipline that can be learned by people from any gender. However, some quantitative research points to the decline of women in mathematics at the collegiate level, graduate school level, and the lack of women in mathematics-related jobs (Cimpian et al., 2016; Corbett \& Hill, 2012; Ryan, 2012). Statistics show that over the past two decades in the USA, the number of degrees awarded to women in Mathematics and Statistics declined. The number of bachelor's degrees awarded went from $46.8 \%$ in 1998 to $42.3 \%$ in 2018 . The number of doctorate's degree went from $31.1 \%$ in 2008 to $28.0 \%$ in 2018 (National Science Foundation, 2021). These numbers are even smaller when we look at the number of women who hold tenure track positions in mathematics at universities, 14.4\% (National Science Foundation, 2018). Mathematics departments across research universities and institutes are houses of the prestigious "mathematicshood," or places where mathematicians live among themselves and produce mathematical knowledge. In such places, there is also the production of identities of mathematicians. The equivalent of the Nobel Prize in mathematics, the Fields Medal, is awarded every four years by the most prestigious mathematical group in the world: the International Mathematical Union (IMU). Usually, a committee chooses between two to four mathematicians to receive the prize at the International Congress of Mathematics (ICM) (Fields medal, n.d.). Surprisingly or not, from 60 recipients from 1938 to 2018, only one woman, Maryam Mirzakhani, has received such an award (Kessel, 2014). In mathematical terms, less than $2 \%$ of Fields medalists are women. Keeping in mind the exclusion of women from mathematics and the percentages showed above; we can conclude that very few women have been credited, recognized, or awarded the highest aspirations in the field of mathematics.

There is also a group of qualitative studies that seek to understand the experiences of women in spaces that are mainly dominated by men, like mathematics. In Gholson's (2016) work, she looked at the intersectionality between race and gender to question how the ideological misconception that 'women cannot do' mathematics has significantly contributed to black girls and women in mathematics becoming part of a group that is overlooked, rendering them 'invisible' (p. 291). Women tend to view

\footnotetext{
${ }^{1}$ I call it the 'so called' gender gap for two reasons. The first is that this gap can be construed as a gap in opportunity rather than as a gap in performance or achievement. The second is that these studies use the term gender, but I would use the term sex because they are largely relying on data sets where sex is the primary variable under investigation.
} 
themselves as 'special' when they successfully occupy and survive in such spaces (see also Walls, 2009). Rodd and Bartholomew (2006) found that women who do succeed in mathematics often pursue positions of invisibility to 'survive' in a field dominated by the opposite gender. Research also indicated that since mathematics is a field dominated by men (Kaiser \& Rogers, 1995; Mendick, 2005a), succeeding in mathematics meant doing masculinities (Mendick, 2005b). I borrow parts of my understanding of doing masculinities from the work of Mendick (2003, 2005b), where she observed that men use mathematics to prove themselves as being able to do things that not everyone can, being economically secure, and proving their reputation as worthy for future employers (p. 236)-doing masculinities functions as an umbrella term, which especially connects to the different tactics men use in the discipline to show power and dominance, as well as comfort, reputation, and security in and for the field of mathematics. Mendick's (2005a) study showed that because of the masculine aspect of mathematics, the field is challenging for men, but even more challenging for women because it is difficult for them to feel comfortable and talented enough to choose mathematics and do well in it (p. 217). Looking through these views, one can argue that women can only survive in mathematical spaces if 1 ) they can do masculinities, or 2) they adapt themselves to do masculinities (Walls 2009). Consequently, mathematics continues to be male-dominated. As argued by Yeh and Rubel (2020), "the masculinization of mathematics can be understood as an exclusionary border for girls and women" (p. 6).

Like a domino effect, the lack of representation of women in mathematics inspired other qualitative researchers to conclude that lack of belonging in the field has been another significant factor influencing women's experiences in mathematics (Herzig, 2010; Solomon, 2007). On the one hand, the work of Herzig (2010) has shown that women still face difficulty to see themselves part of mathematics for many reasons, including the fact that they do not see they belong to the field because of the lack of spaces for possible family aspirations, a continuous need to prove themselves worthy, and surviving in an individualistic field. On the other hand, Solomon (2012), through the analysis of two women's dialogism identifying mathematics students, showed how women have looked for new ways of belonging in mathematics. She concludes that although the field is still masculine, women are reflexive in ways they construct their gendered identities and are aware of gender inequalities in the field. Solomon (2007) positions women as having agency to belong in mathematics whereas Herzig (2010) does not position women with the same agency. Therefore, for Solomon (2007), women are using the heteroglossia of their stories in mathematics to advance in the field where they were once discouraged and denied access. Consequently, women are trying to reconstruct mathematical spaces as more welcoming and collaborative.

Since mathematics has been non-welcoming for women, the research above attests that lack of representation has a strong impact on shaping who gets the opportunities to be part of mathematical spaces and produce mathematical knowledge. I go further and argue that the lack of representation is one of the factors that makes mathematical spaces oppressive for women. Independent of their race, SES, and mathematical capability, women are historically marginalized in mathematics due to their gender identity. Thus, this research uses Freire's (1970/2017) Pedagogy of the Oppressed as a theoretical lens to understand how such oppression functions and possible ways to change the field in the future.

\section{Conceptual Framework}

The Pedagogy of the Oppressed helps this study better understand oppression, conditioned in oppressor and oppressed lives. Freire (1970/2017) defines oppressors as those 'who oppress, exploit, and rape by virtue of their power' (p.44). On the one hand, the oppressor, or the being more fully human, continuously works towards maintaining the oppression so that it makes the oppressed being less human, or dehumanized. From Freire's (1970/2017) theory, I rely on the following definition for dehumanization, 'not only those whose humanity has been stolen, but also (though in a different way) those who have stolen it, is a distortion of the vocation of becoming more fully human' (p. 44). On the other hand, the oppressed may seek change and transformation of the society. The oppressed can never become oppressors because of how the oppressed is conditioned, but they might restore humanized relations and free both the oppressor and the oppressed ( $p$. 44). The transformation process in which the oppressed needs to lead humanity is given by reflection and transformation. Such produce actions and, eventually, liberation (Freire, 1970/2017).

Relying on Gutierrez (2017) and the argument that mathematics itself operates like whiteness since white people are continually receiving credits for the work done in mathematics, I extend to say that mathematics not only operates like whiteness but also as a sexist discipline. Possibly more than race, gender plays an explicit image for mathematics worldwide and dictates whose names are credited for the mathematical knowledge produced. Consistently, credit for the discipline is associated with men, such as Pythagoras, Bhaskara's, and others. Culturally, the subject has achieved an apex and what is conceived of as mathematical knowledge continues to be either 1) perpetuated as it is (we accept the names, the ways of doing, and the truths of mathematics as they are presented in society), or 2) changed and recreated by men since mathematicians are mostly men.

In order to move forward, Freire's Theory of the Oppressed provides lenses to examine what keeps women conditioned in such oppressive situations; he calls these hypothetical places limit-situations. Limit-situations are defined as the border between oppression and freedom. Here, I use the mentoring example brought up by one of the research participants from this study to clarify how the concepts are connected to what is found on the data. In the mentoring example, the research participant says that women need better advising in the department because women do not get advisors that get to know them personally. I see this as a limit-situation for women in the department because, for these women, something is keeping them from having as many opportunities as men in the mathematics field. In Freire's methodology, limit-situations are collected via a dialogical approach, which means created by, and with, the oppressed during the data collection phase of a study. In limit-situations, we also find the generative themes of oppression. These themes are defined by Freire (1970/2017) as 'thought-language with which men and women refer to reality, the levels at which they perceive that reality, and their view of the world' (p. 97). Therefore, a generative theme associated with the limit-situation exemplified above would be the unjust, inequitable, and unequal mentoring provided to students from different genders. Also, limit-situations are found in the contradictions that lie within women's experiences. 
Contradictions are the struggles existing in the oppressor-oppressed relation. Through Freire's theory, these contradictions (the unity and struggles of opposites) are informed by the themes found in women's narratives as they talk about their experiences. One example of a contradiction related to the mentoring example discussed above is found on the following passage: 'Definitely have more women professors and try to get them to mentor more. We want to have more women and mentors that mentor us to the level that men can mentor.' This is seen as a contradiction because it is a unified struggle (not having women that can mentor to the level men can) that makes the research participant discontent with the field (they do not have equal mentoring). I borrow the following definition of contradiction from the work of Chauí (1980):

Generally, we confuse contradiction and opposition, but these are very different concepts. In opposition, there are two terms, which have each of its characteristics and its existence, which oppose each other when, for some reason, they meet. This means, in opposition, we can take the two terms separately, understand each of them, understand why they will oppose each other if they meet, and, above all, we can see that they exist and can be maintained if there be opposition or not. Thus, for example, we could imagine that the terms 'master' and 'slave' are opposites, and this does not stop us from taking each of these concepts separately, verifying their characteristics, and understanding why they oppose each other. Contradiction, however, is not this. In contradiction, there is only the relation; that is, we cannot take the antagonistic terms outside of this relation. They are created by this relation and transformed in it and by it (pp. 37-38, translated from Portuguese).

Therefore, the contradictions in this study are the discursive struggles that women encounter in mathematical spaces, which only exists because of the oppressed-oppressor relationship in which they are conditioned.

In closing, by relying on theoretical approaches for understanding oppression, this research argues that mathematical spaces are systematically operating by themselves to further women's oppression because they are set up to maintain women as oppressed and men as oppressors.

\section{METHODOLOGY AND METHODS}

\section{Researcher Positionality}

In this section, I discuss my positionality since it directly impacts how I discuss and address the findings of this research. I was born and raised in a small rural area 30 miles from Brasilia, Brazil. Growing up, I had many identities that are often framed as deficits/deficiencies within Brazilian society at large. I was poor, dark-skinned, lived in a rural area, and gay. These combinations of identities taught me early in life about inequalities and motivated me to fight against inequities. My research interest is in the ways gender and sexual identities influence one's mathematical identity. More specifically, I am currently interested in understanding how students from historically marginalized gender and sexual identities respond to high school mathematical lessons exploring social injustices.

My identity influenced the data analysis and findings of this research since my gender identity is not the same as my participants' identities. I identify as a man, while my participants identify as women. While I didn't have the chance to do member checks of the findings with my research participants, I used inductive coding (Thomas, 2003) and had multiple woman researchers help me check my codes and analysis to ensure the validity of the findings.

\section{Participants}

To collect the data for this study, six women PhD students in different stages of their program were selected. In October 2019, I emailed the PhD students posted on the graduate student directory website of a large research institution located in the Midwestern United States (pseudonym Frank University). This institution was strategically chosen, as it has one of the highestranking PhD programs in mathematics in the United States. In the primary email, I provided general information about the study (project investigators, researchers' affiliation, commitment required, and payment for participation) and eight students were interested in participating. They were then given a demographic survey providing their age, race/ethnicity and gender identities, the country where they were from, the highest level of mathematics classes they took, and their grades in those classes. As selection criteria, I selected participants identifying as women and high achievers in mathematics according to their grades in the highest math classes taken. Race and nationality were not criteria for selecting participants. Six students were selected to participate. I choose two in the beginning of their studies, two in the middle, and another two in the end, so that I could have a thorough understanding of these students' experiences throughout each stage of the PhD program.

Most of the participants either planned on teaching (working for small liberal arts colleges) or doing research (working for research-focused universities) as future jobs. For this paper, I present data from two students, both in the final stage of their PhD, because their experiences serve as representative of the themes found across all six interviews. I chose one student that strongly showed interest in teaching (pseudonym: Kelly) and one that showed interest in doing research (pseudonym: Jennifer). This study uses these two students' experiences to foreground women's different narratives created by conflicts and contradictions that permeate women's oppression in mathematical spaces.

\section{Data Collection}

Methodologically, this research uses a life-story interview approach, where lead-off questions were used to guide storytelling, and follow-up questions allowed discussion of things brought up by the students (McAdams, 2008). Using such methodology and what it encompasses, I developed a two-day semi-structured interview in which students had the opportunity to reconstruct their life stories in mathematics. On the first day of interviews, the researcher's goal was to become familiar with the participants and 
how they experienced mathematical spaces. A series of questions were posed so that participants could elaborate on their experiences. Questions were asked about their:

- perception of work opportunities

- ability to do mathematics

- the choice to study mathematics

- mathematician identity or identities

- beliefs about mathematicians

- stereotypes in mathematics

On the second day, students were asked to reconstruct their whole lives in these mathematical spaces, from elementary education to their PhD program. Students also had the opportunity to discuss gender as a whole and, more specifically, gender issues in their math department. The questions focused on:

- gender issues in U.S. society

- construction of gender identity

- perception of gender stereotypes

- gender stereotypes in the math department

\section{Data Analysis}

The methodological approach was designed under the Theory of the Oppressed by Freire (1970/2017). First, I started by finding limit-situations through an intensive review of past literature and bringing together what has been discussed concerning gender issues in mathematics. Then, I presented the problem as questions to understand what the participants had to say. Second, this study analyzed the data collected and codified it. Such codification helped to map the generative themes that create women's oppression in the department of mathematics.

Following Freire's theory, the second stage of this study occurred by looking at the contradictions on the generative themes presented by the oppressed. In the second stage, I also had the opportunity to add new themes, defined by Freire (1970/2017) as hinged themes (themes not previously suggested), to what I observed based on interview data.

Freire's proposed methodology in Pedagogy of the Oppressed suggests a checkup with the oppressed to decode the second stage's findings. Such a checkup encompasses a $3^{\text {rd }}$ stage. After de-codification, the researchers have the opportunity to write final auxiliary material for the oppressor to help them to reflect on act-limits to liberate themselves and the world from the oppression (limit-situations) encountered ( $4^{\text {th }}$ stage). This is the dialogical approach in Freire's methodology. The $3^{\text {rd }}$ and 4 th stages of Freire's methodology were not developed in the study presented in this article due to the lack of time and financial resources. All data were analyzed, from transcription to results, with the support of a qualitative data analysis software (MAXQDA).

\section{FINDINGS}

\section{1st Day}

\section{Jennifer - Mathematics as a lifelong challenge}

Jennifer was a sixth-year PhD student, originally from Uruguay. In many ways, Jennifer's story is particularly interesting. She grew up in Uruguay and was raised by PhD parents who worked with research for a university in Uruguay. According to her, it always felt natural to become as specialized as she could in whatever area she decided to pursue. Growing up, Jennifer was amazed by reading and writing, but never really saw a lifelong challenge in that; instead, she saw it in math.

Perseverance as a Result of Frustration: Even though she never considered herself good at mathematics, she believed some people just had an innate mathematical ability. She knew she could get better if she had enough self-determination to do so. She thought that people do not need to be smart to become mathematicians, and that, when they are not smart, persevering might be more comfortable in mathematics, since they are already used to the frustration of not being good (not achieving rapid success). She also felt that this was a particular characteristic that happened to her, so she never gave up on mathematics [see Appendix A.1 for transcripts]. The orchestration of narratives creates the first contradiction in Jennifer's story. She thinks that ability does not define success and that she is not brilliant in mathematics and that one does not need to be good to be successful, but rather her success is contingent upon her willingness to experience not feeling good. Such an understanding opposes the societal way to think about a successful PhD student in mathematics, which is unique.

She strongly feels that the average PhD mathematics student is usually either someone who loves math or loves teaching math. She does not think that people who just love math should be doing a PhD, because graduate school in mathematics requires one to be more than good; it is necessary to ask questions critically, rather than just solve math problems. Regarding people who love teaching, she thinks that they should be pursuing a PhD in Mathematics Education instead.

Order in the Middle of Chaos: Her primary views on mathematicians are that they are not very organized, which becomes apparent when she talks about professors or students who 'do' pure mathematics. It seems that there is a specific lifestyle inside mathematical spaces for those people. For example, Jennifer explains why she decided to pursue mathematics and expresses her beliefs about mathematicians [see Appendix A.2 for transcripts]. Jennifer's narrative leads to another contradiction. She can see 
the order in the middle of chaos, she feels grounded by mathematics, and it informs her that her success and engagement with the field will not be affected by any difficulties because even in the chaos, she sees the order that gives her ground.

Finally, it is very intriguing how experiences of fear, discomfort, and feeling useless have been normalized by Jennifer to explain how she navigates and succeeds in mathematical spaces [see Appendix A.3 for three excerpts where these themes appeared, respectively]. All the excerpts are useful for understanding the contradictions on what life is like inside the mathematics department for a woman. Below, under the $2^{\text {nd }}$ day, I present how contradictions have shaped Jennifer's experiences as a woman doing mathematics. Her contribution to understanding additional themes that work against women's success is presented in the Discussion and Conclusion section of this paper.

\section{Kelly - Teaching as passion}

The second participant chosen for this paper was Kelly, a white woman born in the United States. Similar to Jennifer, Kelly is also on the final stage of her doctoral studies, and she is very knowledgeable about what it takes to be a good mathematician. In particular, Kelly's interest in teaching is what caught my attention during her interview, and particularly in this analysis. It was informative to compare the experiences of Jennifer and Kelly to understand better how these students with different interests (teaching vs. researching) navigated the PhD program and what themes were generated as they talked about their experiences.

Kelly grew up with parents that always encouraged her to pursue education. Even though her parents were not in academia, they always expected her to do well. Because of her dedication towards her studies, she never faced any problem in being a higher achiever in mathematics. Since elementary school, she knew that she wanted to teach mathematics and that as she got into higher grades, she became more passionate about the mathematical topics she learned. When she was finally done with college, she knew she wanted to teach college-level mathematics and would need to pursue a PhD. This is the primary reason she gave for becoming a mathematics PhD student.

Trapped in the 'Wrong' Field: One contradiction from the very beginning of her graduate school story is that she did not know much about the possibilities to pursue a PhD in mathematics education; instead, she was told that in order to teach mathematics for college, she needed to pursue a PhD in mathematics, which can be misleading. Throughout her Ph. D. program, she found challenges related to her area of interest in mathematics. As she got more information about doctoral programs, she finally realized that she could do a PhD in Mathematics Education to teach college students and that this would also give her a better preparation to teach mathematics for college in the future. Such a discovery made Kelly decide to change her dissertation topic towards the end of her degree. Consequently, she also needed to change advisors and find one with double appointments in the Math Department and School of Education at Frank University [see Appendix A.4 for transcripts]. The information received before going to graduate school occasioned many negative experiences for Kelly and made her focus on the wrong field for many years.

It is also noticeable that Kelly's love for mathematics and passion for teaching gave her a particularly hard time to navigate her doctoral program. She expressed that there was a lack of advisory support towards what graduate students should research, that the process for being qualified was the completion of outdated qualification examinations, and that the program took her many years of dedication in order to accomplish the requirements for the degree.

Kelly mainly felt the atmosphere at her department was great and that she always could find support, even though sometimes such support was not the best. She continually said people were kind to her, including professors and graduate peers. When asked about what is required of a student to pursue a PhD in mathematics, she stated they need to be more than just passionate about mathematics. It requires dedication because the program is hard, and it takes a considerable time sacrifice since it is a long program. The unity of her struggles (contradiction) is found in dealing with the lack of guidance in an inclusive graduate mathematics program.

Table 1. Generative themes and women experiences in mathematical spaces

\begin{tabular}{ll}
\hline Generative Themes & Women in Mathematical Spaces \\
\hline Success & Result of perseverance through experiences of not feeling good. Success comes with more than just passion for \\
mathematics since the PhD is a long program and requires many sacrifices (also see Lubienski \& Ataide Pinheiro, 2020) \\
- Feeling grounded and seeing a higher purpose in mathematics chaos \\
- Conditioned by fear, discomfort, and uselessness \\
- Werds of affirmation can boost one's mathematical confidence \\
- years that she ended up not pursuing) \\
- Lack of advice for possibilities of research area dealing with qualifying exams in a women inclusive program \\
- Lack of confidence because one can't memorize/learn any more in the graduate program, which contributes to the \\
feeling of not belonging
\end{tabular}

\section{2nd Day}

\section{Jennifer- Take us personally}

As Jennifer continued to reflect on her Ph. D. program experiences, another contradiction is found in her story. She mentioned that she needed to develop a thick skin to handle oppressions in mathematical spaces. This thick skin was grown as a protection because of the varieties of experiences she had related to her gender. When I asked her if there was any frustration she ever encountered in mathematics because she is a woman, she said: 
I do not know if it has to do with mathematics specifically, but just being in such a male-centered field. It's really annoying to have to deal with any sort of rumors or people talking behind your back that eventually gets back to you, [... ] it's always guys. [...] So, in that sense, I don't know if it's mathematics, but sometimes just having a little boys club creates a hostile environment and you cannot just let it get to you. So, you just have to be really, like kind of aggressive and not care, but it's hard to not care.

In the passage above, the contradiction is built from the fact that nobody should need to develop a thick skin to survive in the mathematics department.

Another contradiction that was repeatedly presented by Jennifer connects to the fact that she felt disadvantaged by the entire range of ways mentoring functions in the mathematics department. Firstly, she commented that there are more men than women professors, which is a big issue. Nevertheless, she brought forward that there was a creation of a 'boys club' in the department, and it influenced a lot of women's progress towards their PhD and future careers [see Appendix A.5 for her response to her feelings as a woman doing a PhD in mathematics].

In Appendix A.5, it becomes clear that Jennifer is not satisfied with the hurdles she needs to overcome because of her gender (contradiction). She points to the lack of camaraderie among women compared to how close men are to one another, which she understood as contributing to men's future opportunities. She sees that in a field mostly occupied by men, men help and support each other to be successful, once again forcing women who want to succeed in the field to work even harder to achieve the same level of success.

She argues that there is a need for more women in the field, especially women in power (professors). Also, there is a need for women to protect and support each other because that is what men have done. When asked what her opinion on the gender makeup of the department was, Jennifer said:

I do think that there could be more women. [...] I definitely feel like it could be better, especially at the higher levels, because it has to work out from the top. [...] 50/50 professor, you know, the power would be, more women will call out these guys that are kind of like creating this little boys club that would be like, okay, hold on because my kids are being affected by your kids, you know, you would have these little like turf wars and then they would help set us straight, instead of us having to fight them (boys) ourselves. So that there's no unprofessional behavior from a student towards a professor. It should be the other way around.

Her advocacy in the passage above is followed by a robust contradiction that recurred for Jennifer. We need more and stronger women, she said. Women cannot let inequities be normalized in the department and should call out these inequities when they occur.

The passages above particularly moved me to ask how to improve women's experiences in the mathematics department. Jennifer responded:

Definitely have more women professors and try to get them to mentor more. We want to have more women and mentors that mentor us to the level that men can mentor. Why don't we get taken out to a bar and hang out with our advisor and be taught all these things? Why don't we get taking our speakers to another formal setting? Why is that always the guys? So, I feel like in that sense, we need women mentors. Women that feel involved, you know, invested [...] we need people to get their hands dirty with the kids. And I feel like that sounds like women are failing us like the older ones (older women professors in her department), they are failing us. And they don't hang out among themselves either. There are very few interactions among faculty. But it's even less among women, I've never seen two women together in the department.

Jennifer is hopeful that a new generation of woman professors, alongside older faculty members, can start a revolution in the department and take mentoring to a higher level. She calls for women advisors to provide equal mentoring with the goal of correcting inequities that hinder women's success in mathematical spaces.

\section{Kelly - Getting off track for good}

Kelly had always been very confident in her mathematical abilities and placed in advanced mathematics classes. She never personally believed she was good at math, although she had often heard her parents (especially her mother) and her teachers giving her the affirmation: 'you are good.' She affirmed that she mostly worked on her own and never really needed or wanted to bother her peers with her mathematics doubts: she would just give more thought to whatever she was working on, which would be sufficient to answer her questions. Such experiences were repeated throughout K-12. However, Kelly talked about how lonely she felt in college, after being encouraged by a professor to pursue an R.U. summer research camp in mathematics because she did not have anybody to work with her. She mentioned that it was a very individual-centered camp, and she did not like it [see Appendix A.6 for transcripts]. As much as Kelly seemed pretty unmotivated with the situation (contradiction), it can also be related to the fact that she did not have someone she could reach out to for help in those circumstances. This caused her discontent with the situation, as she mentioned throughout her interviews that sometimes just knowing there was an option made her feel better.

Kelly - I had a really good memory I no longer have: Kelly talked about how she understands mathematics as fun and cool when teachers can teach well and help students fix the content in their minds, which she describes as learning. We can see this in the passage below as she talks about positive impressions of mathematics teachers at the elementary/middle school levels.

So, my fifth-grade teacher, Mr. O'Conner, was really great. And he made things very interesting and fun. This wouldn't be allowed today. But I will never forget the rule for dividing fractions, you flip it and multiply, because he called two kids up to 
the front of the room. And he said, okay, these kids are two fractions. If we want to divide this person by this person, picks up the second kid, you just flip them and multiply. So he would probably get in trouble for that now. But we all learned. So that was really good.

As she describes in the passage above, 'I will never forget,' 'it was really good,' and 'we all learned.' These sentences mark the importance of being able to memorize something and, consequently, learning. However, Kelly reports that her confidence in mathematics has diminished by half during the mathematics PhD program. One of the reasons is that she can no longer memorize and just rattle off a theorem as much as she feels other students can.

After I left yesterday, another thing that I thought of those moments when I felt like I didn't belong this much, was sort of a similar thing, where there are some people in this program who just read something, and they remember it. They can rattle off a theorem, like It's nothing. And I always thought that I had a really good memory, up until I came here. And all of a sudden, I don't have a memory, like theirs.

The contradiction created through her confidence in mathematics and not thinking she can learn, memorize, or fix things in her mind, has contributed to her feelings of not belonging in the program (ways that women do not belong in mathematics are results also found by Herzig, 2006; Solomon, 2007). Kelly also felt that her mathematical confidence diminished because of a period of depression she encountered at the beginning of her Ph. D. student journey.

Another contradiction that is emergent throughout her interviews is the importance of words of affirmation. The passage below, Kelly tells her experience telling her advisor she wants to switch topics for her dissertation.

So, when I approached him to tell him that I wanted to switch things, I could not fathom a response other than do what you want to do. And he tried to convince me to stay and finish doing algebra with him. And he told me that he thought I was doing really well, and that he thought I should finish working in abstract algebra. That was the first time I heard that kind of affirmation from him. So, in a weird way, I think switching topics boosted my confidence just to hear that.

Positive affirmation is something that Kelly teaches us that is very valuable for graduate students, as she told me towards the end of the interview that her confidence has gotten better because her former advisor said she was doing well in the PhD program and should keep doing her research in algebra instead of transitioning to education. The contradictions in her lack of confidence and ability to boost it up or down because of affirmation words show us the importance of encouragement in someone's mathematical path.

\section{Jennifer and Kelly - Contradictions within}

Kelly and Jennifer have different perspectives on the gender makeup of the mathematics department. Kelly consistently said that there are fewer women PhD students than there are men. For Jennifer, at the graduate level, feels such a split is almost 50/50. However, Jennifer does comment on more women PhD students dropping out from the program, which creates at times a difference in the gender makeup of the program. In addition to women dropouts, according to Jennifer, it usually happens because women find out the program is not what they want for their lives, and research has shown it could also be connected with many other issues, such as: women are more interested in teaching than doing research, consider family-related decisions when making plans for future career, and lose their confidence in mathematics throughout the PhD program (see Lubienski \& Ataide Pinheiro, 2020). Kelly does state her discontent with such imbalance in number of man and woman PhD students; she expressed hope that we could have already changed this situation by this time and have more women in mathematics. She said, 'I feel sad about the grad students. Because I feel like at this point, I would have hoped that things were more equal by now.'

Such discontent shows us the hope women have for having more women in the field, which unfortunately is still an issue. A final struggle that was introduced by Jennifer and is also a vivid experience for Kelly is connected to mentorship. Kelly thinks it is crucial to have more professors who can provide a good mentorship since there is an imbalance in these mentorships' quality. To finalize, she says there is a need to have mentors who can connect more personally with students because otherwise, she would not trust important information about her life and the hurdles she is going through with someone who only connects with her academically.

I would do just kind of for all the grad students of having like more of like a quality mentorship kind of a thing. I think they're trying to have that happen. But some of the mentors are more helpful than others. And some of them connect more personally than others do. It's hard for me to open up to someone about different things that I'm dealing with, if there's not that sort of personal part.[...] I'm not going to tell someone who l've only had academic conversations with about that, other than in really vague terms of like, I'm dealing with some personal stuff. But if there's sort of that a little bit more of that personal connection, then I can actually talk to them about it.

Table 2. Generative themes and gendered experiences in mathematical spaces

\begin{tabular}{ll}
\hline Generative Themes & Gendered Experiences in Mathematical Spaces \\
\hline Mentoring & $\bullet$ Gender make-up of the mathematics department mostly favors men \\
& $\bullet$ Lack of camaraderie among women compared to men, which contributes to men's success (e.g., "boys club) \\
& $\bullet$ Men are more likely to build personal relationships with other men, which contributes to men's success. Quality in \\
& mentorship varies, and there is a need for faculty that can connect with PhD students more personally \\
\hline Thick Skin & $\bullet$ You need to become aggressive and not care about rumors men create against you. It is hard not to care \\
\hline
\end{tabular}


This is a significant finding for this study, as by the experiences presented, women felt men were able to more personally connect with their advisors.

\section{DISCUSSION AND CONCLUSION}

This paper had the intention to narrate women PhD students' stories through Freirean lenses. This research was particularly interested in finding out the nature of contradictions of these women's narratives that occasioned struggles that tell us the generative themes that shape women's experience in mathematics. Such work was much needed since there is the only possibility for change in the inequality women live in mathematics if we can find the limit-situations that limit women's pursuit of freedom in mathematics to "be more" (Feire, 1970/2017).

Many of the findings encountered in this study were already reported elsewhere, by other studies: isolation (Herzig, 2004; Johnson, 2011), mathematics as a masculine field (Mendick, 2006), lack of confidence (Ganley \& Lubienski, 2016), feeling of not belonging to mathematics (Herzig, 2010; Solomon, 2007), and many others are not new. Less research was done by looking at mathematics as an oppressive space through Freirean lenses and tried to understand the contradictions in these stories that affords us to uncover struggles women go through in mathematics. The need to develop a thick skin and adapt oneself to be more aggressive are things that women should not be going through in mathematical spaces. Such narratives lead this study to two points, 1) women who cannot develop a thicker skin either leave the field or suffer a lot, and 2) women need to go through a process of transformation men do not have to go through to survive in those spaces. Jennifer 'ease' on being a successful mathematics PhD student was constantly conditioned by the fact that even though there are many injustices happening in the program, she never let it get to her because of the thicker skin she developed. These two findings points to gender inequity and negatively impacts women's success in the field, as those who haven't or aren't able to go through a process of transformation of a 'thicker skin' usually won't be able to succeed in the field of mathematics. This finding takes us back to studies such as Mendick (2006): is aggressiveness a masculine characteristic that women need to have to succeed in mathematics?

Kelly's importance given to words of affirmation is a very informant to researchers, since in many cases, depending on whether the affirmation is positive or negative, it could have a drastic impact on one's success, particularly women, who already need to go through a hard path in such a male-centered field. Qualitatively, this finding brings back the discussion of whether affirmations influence students' engagement with mathematics, which Bancroft, Bratter, and Rowley (2017) found insignificant in a quantitative study with high school girls. Participants varied in terms of how they saw/felt the gender makeup at Frank University among Ph. D. students; however, all of them said that there were more men than women when looking at faculty. This finding indicates that the field of mathematics has not changed even after much research showing mathematics to be a male-dominated field.

This study also found that men in the mathematics department take men more personally, which causes an imbalance in the level of mentorship men and women get. Jennifer and Kelly both advocated for the dismantling of the PhD as the 'all-boys club,' where male professors bound together with male students in a more personal way. As Jennifer mentioned, such things are advantages women do not have since professors can get to know male students on a whole different level that goes beyond just mathematics. This contradiction contributes to a whole system oppression woman goes through in mathematics. Consequently, all 'boys clubs' continue to be propagated, and mathematics perpetuates as a masculine (Mendick, 2006) and a sexist field. There is also a need for change in men's behavior in the department and the need for more women mentors who can connect with women PhD students in a personal way.

This study has many limitations, such as describing students' narratives in only one PhD program and not analyzing the intersectionality of these students' experiences, such as how these students' gender is racialized, since they have different races (May, 2015). Intersectionality is important because it could bring more nuances to this study's findings since multiple forms of power and inequality might simultaneously affect the lives of these women. Also, Frank University is an institution that has been fully engaged with the WAM (Women Association of Mathematics), which could also have a significant and positive impact on these women's experiences. Future studies are needed to complement the Freirean methodology work started in this research and investigate ways for mentoring programs to serve students from all genders equitably, including women. In order to complement Freirean methodology, it is needed to have a recorded meeting with research participants presenting the themes found by this study and discussing them. Then, a group of researchers will meet and analyze the recorded meeting again, with the presence of the research participants. The principal investigator must challenge and problematize the discussion so that the participants are able to comment on all the feelings of frustrations that wouldn't be able to be obtained elsewhere (Freire, 1970/2017, pp. 155-157). The last phase of Freirean methodology happens when investigators begin a systematic and interdisciplinary study on the findings (p. 159).

Author contributions: All authors have sufficiently contributed to the study, and agreed with the results and conclusions.

Funding: The research reported in this article was supported by the MAXQDA Research Grands under the 2019 \#ResearchforChange Grant.

Declaration of interest: No conflict of interest is declared by authors. 


\section{REFERENCES}

Ahlqvist, S., London, B., \& Rosenthal, L. (2013). Unstable identity compatibility: How gender rejection sensitivity undermines the success of women in science, technology, engineering, and mathematics fields. Psychological Science, 24(9), $1644-1652$. https://doi.org/10.1177/0956797613476048

Bancroft, A., Bratter, J., \& Rowley, K. (2017). Affirmation effects on math scores: The importance of high school track. Social Science Research, 64, 319-333. https://doi.org/10.1016/j.ssresearch.2016.10.001

Boaler, J. (2000). Mathematics from another world: Traditional communities and the alienation of learners. The Journal of Mathematical Behavior, 18(4), 379-397. https://doi.org/10.1016/S0732-3123(00)00026-2

Braathe, H. J., \& Solomon, Y. (2015). Choosing mathematics: the narrative of the self as a site of agency. Educational Studies in Mathematics, 89(2), 151-166. https://doi.org/10.1007/s10649-014-9585-8

Butler, J. (1990). Gender trouble: Feminism and the subversion of identity. Routledge.

Butler, J. (2004). Undoing gender. Routledge. https://doi.org/10.4324/9780203499627

Chauí, M. (1980). O que é Ideologia? Brasiliense.

Chronaki, A., \& Pechtelidis, Y. (2012). 'Being Good' at Maths: fabricating Gender Subjectivity. REDIMAT-Journal of Research in Mathematics Education, 1(3), 246-277. https://doi.org/10.4471/redimat.2012.14

Cimpian, J. R., Lubienski, S. T., Timmer, J. D., Makowski, M. B., \& Miller, E. K. (2016). Have gender gaps in math closed? Achievement, teacher perceptions, and learning behaviors across two ECLS-K cohorts. AERA Open, 2(4), 2332858416673617. https://doi.org/10.1177/2332858416673617

Corbett, C., \& Hill, C. (2012). Graduating to a pay gap: The earnings of women and men one yearafter college graduation. American Association of University Women.

Damarin, S. K. (2000). The mathematically able as a marked category. Gender and Education, $12(1), 69-85$. https://doi.org/10.1080/09540250020418

Damarin, S., \& Erchick, D. B. (2010). Toward clarifying the meanings of gender in mathematics education research. Journal for Research in Mathematics Education, 41(4), 310-323. https://doi.org/10.5951/jresematheduc.41.4.0310

Esmonde, I. (2011). Snips and snails and puppy dogs'tails: genderism and mathematics education. For the Learning of Mathematics, 31(2), 27-31. https://doi.org/10.2307/41319563

Esmonde, I., \& Langer-Osuna, J. M. (2013). Power in numbers: student participation in mathematical discussions in heterogeneous spaces. Journal for Research in Mathematics Education, 44(1), 288-315. https://doi.org/10.5951/jresematheduc.44.1.0288

Fennema, E., \& Sherman, J. (1977). Sex-related differences in mathematics achievement, spatial visualization and affective factors. American educational research journal, 14(1), 51-71. https://doi.org/10.3102/00028312014001051

Fennema, E., Carpenter, T. P., Jacobs, V. R., Franke, M. L., \& Levi, L. W. (1998). A longitudinal study of gender differences in young children's mathematical thinking. Educational researcher, 27(5), 6-11. https://doi.org/10.3102/0013189X027005006

Fields medal. (n.d.). https://www.mathunion.org/imu-awards/fields-medal

Freire, P. (1970/2017). Pedagogia do oprimido (64th ed.). Paz \& Terra.

Gholson, M. L. (2016). Clean corners and algebra: a critical examination of the constructed invisibility of black girls and women in mathematics. The Journal of Negro Education, 85(3), 290-301. https://doi.org/10.7709/jnegroeducation.85.3.0290

Good, C., Rattan, A., \& Dweck, C. S. (2012). Why do women opt out? Sense of belonging and women's representation in mathematics. Journal of personality and social psychology, 102(4), 700. https://doi.org/10.1037/a0026659

Gutiérrez, R. (2002). Enabling the practice of mathematics teachers in context: toward a new equity research agenda. Mathematical Thinking and Learning, 4(2-3), 145-187. https://doi.org/10.1207/S15327833MTL04023_4

Gutiérrez, R. (2017). Why mathematics (Education) was late to the backlash party: the need for a revolution. Journal of Urban Mathematics Education, 10(2), 8-24. https://doi.org/10.21423/jume-v10i2a347

Hall, J., \& Suurtamm, C. (2018). Behind the 'Success Story': exploring the Experiences of a Woman Mathematics Major. Canadian Journal of Science, Mathematics and Technology Education, 18(4), 342-354. https://doi.org/10.1007/s42330-018-0032-1

Herzig, A. H. (2004). Becoming mathematicians: women and students of color choosing and leaving doctoral mathematics. Review of Educational Research, 74(2), 171-214. https://doi.org/10.3102/00346543074002171

Herzig, A. H. (2010). Women belonging in the social worlds of graduate mathematics. The Mathematics Enthusiast, 7(2), $177-208$. Available at: https://scholarworks.umt.edu/tme/vol7/iss2/2

Hyde, J. S., Fennema, E., \& Lamon, S. J. (1990). Gender differences in mathematics performance: a meta-analysis. Psychological bulletin, 107(2), 139. https://doi.org/10.1037/0033-2909.107.2.139

Johnson, D. R. (2011). Women of color in science, technology, engineering, and mathematics (STEM). New Directions for Institutional Research, 2011(152), 75-85. https://doi.org/10.1002/ir.410

Kaiser, G. \& Rogers, P. (1995). Introduction: equity in mathematics education. In P. Rogers \& G. Kaiser (Eds.), Equity in mathematics education: influences of feminism and culture (pp. 1-10). The Falmer Press. 
Kessel, C. (2014). Understanding underrepresentation: Women in mathematics and other fields. The Mathematical Intelligencer, 36(4), 10-18. https://doi.org/10.1007/s00283-013-9441-1

Leyva, L. (2017). Unpacking the male superiority myth and masculinization of mathematics at the intersections: A review of research on gender in mathematics education. Journal for Research in Mathematics Education, 48(4), $397-452$. https://doi.org/10.5951/jresematheduc.48.4.0397

Lubienski, S. T., \& Ganley, C. M. (2017). Research on gender and mathematics. In J. Cai (Ed.), Compendium for research in mathematics education (pp. 649-666). National Council of Teachers of Mathematics.

Lubienski, S. T., Robinson, J. P., Crane, C. C., \& Ganley, C. M. (2013). Girls' and boys' mathematics achievement, affect, and experiences: Findings from ECLS-K. Journal for Research in Mathematics Education, 44(4), 634-645. https://doi.org/10.5951/jresematheduc.44.4.0634

Lubienski, S., \& Ataide Pinheiro, W. (2020). Gender and Mathematics: what can other disciplines tell us? What is our role? Journal of Urban Mathematics Education, 13, 1-14. https://doi.org/10.21423/jume-v13i1a377

Man-Keung, S. (2000). The ABCD of using history of mathematics in the (undergraduate) classroom. Paleontological Society Papers, 6, 3-10.

May, V. M. (2015). Pursuing intersectionality, unsettling dominant imaginaries. Routledge. https://doi.org/10.4324/9780203141991

McAdams, D. P. (2008). Personal narratives and the life story. In O. John, R. Robins, \& L. Pervin (Eds.), Handbook of personality: Theory and research (pp. 241-261). Guilford Press.

Mendick, H. (2003). Choosing maths/doing gender: A look at why there are more boys than girls in advanced mathematics classes in England. In L. Burton (Ed.), Which way social justice in mathematics education? (pp. 169-187). Praeger.

Mendick, H. (2005a). A beautiful myth? The gendering of being/doing 'good at maths'. Gender and education, 17(2), $203-219$. https://doi.org/10.1080/0954025042000301465

Mendick, H. (2005b). Mathematical stories: why do more boys than girls choose to study mathematics at AS-level in England? British Journal of Sociology of Education, 26(2), 235-251. https://doi.org/10.1080/0142569042000294192

Mendick, H. (2006). Masculinities in mathematics. Open University Press.

Mohanty, C. (1988). Under Western eyes: Feminist scholarship and colonial discourses. Feminist review, 30(1), 61-88. https://doi.org/10.2307/1395054

National Science Foundation, National Center for Science and Engineering Statistics. (2021). Women, minorities, and persons with disabilities in science and engineering: 2021. NSF 21-321. Alexandria, VA. https://ncses.nsf.gov/pubs/nsf21321/report/field-ofdegree-women

National Science Foundation, National Science Board. (2018). Science and engineering indicators: 2018. Report NSB-2018-1. Alexandria, VA. https://nsf.gov/statistics/2018/nsb20181/report

Renold, E., \& Allan, A. (2006). Bright and beautiful: high achieving girls, ambivalent femininities, and the feminization of success in the primary school. Discourse: studies in the cultural politics of education, 27(4), 457-473. https://doi.org/10.1080/01596300600988606

Rodd, M., \& Bartholomew, H. (2006). Invisible and special: Young women's experiences as undergraduate mathematics students. Gender and Education, 18(1), 35-50. https://doi.org/10.1080/09540250500195093

Rubel, L. H., \& Ehrenfeld, N. (2020). Palestinian/Arab Israeli women's experiences in mathematics education: An intersectional analysis. International Journal of Educational Research, 102, 101616. https://doi.org/10.1016/j.ijer.2020.101616

Rudrappa, S. (2015). Discounted life: The price of global surrogacy in India. NYU Press. https://doi.org/10.18574/nyu/9781479874521.001.0001

Ryan, C. (2012). Field of degree and earnings by selected employment characteristics: 2011.U.S. Department of Commerce, Economics and Statistics Administration, U.S. Census Bureau. https://www2.census.gov/library/publications/2012/acs/acsbr11-10.pdf

Solomon, Y. (2007). Not belonging? What makes a functional learner identity in undergraduate mathematics? Studies in Higher Education, 32(1), 79-96. https://doi.org/10.1080/03075070601099473

Solomon, Y. (2012). Finding a voice? Narrating the female self in mathematics. Educational Studies in Mathematics, 80(1-2), 171183. https://doi.org/10.1007/s10649-012-9384-z

Solomon, Y., Radovic, D., \& Black, L. (2016). 'I can actually be very feminine here': contradiction and hybridity in becoming a female mathematician. Educational Studies in Mathematics, 91(1), 55-71. https://doi.org/10.1007/s10649-015-9649-4

Stedall, J. (2012). The history of mathematics: A very short introduction (Vol. 305). Oxford University Press. https://doi.org/10.1093/actrade/9780199599684.001.0001

Steele, J. R., Reisz, L., Williams, A., \& Kawakami, K. (2007). Women in mathematics: Examining the hidden barriers that gender stereotypes can impose. Women and minorities in science, technology, engineering and mathematics: Upping the numbers, 159183. https://doi.org/10.4337/9781847206879.00017

Thomas, D. R. (2003). A general inductive approach for qualitative data analysis. School of Population Health, University of Auckland, New Zealand. 
Walker, E. N. (2012). Cultivating mathematics identities in and out of school and in between. Journal of Urban Mathematics Education, 5(1), 66-83. https://doi.org/10.21423/jume-v5i1a173

Walls, F. (2008). Girls, mathematics and the gendered construction of mathematical (dis)ability. Paper presented at the PME. http://www.pme32na30.org.mx/ws1/Gender\%20and\%20Mathematics\%20book\%20Abstract-walls.pdf

Walls, F. (2009). Mathematical subjects: Children talk about their mathematics lives. Springer.

Yeh, C., \& Rubel, L. (2020). Queering mathematics: Disrupting binary oppositions in mathematics pre-service teacher education. In N. Radakovic \& L. Jao (Eds.), Borders in mathematics pre-service teacher education (pp. 227-243). Springer. https://doi.org/10.1007/978-3-030-44292-7_11 


\section{APPENDIX A}

\section{Transcripts}

\section{A.1}

I've seen so many kids just feel really frustrated. Because in So what happens is, you know, they pass their quals, that's a reward in itself. Oh, these kids that were brilliant students, they take one class, they excel, they take all the classes, and they're brilliant professionals, like, oh, you're smart, you're amazing, can solve all these problems. And then you give them a real problem that hasn't been solved before. Not one that, you know, is used as an exam question in every single, you know, like, I don't know, analysis class or anything. And that is when the real, you know, ability of a person as a mathematician relation, you know, pop up. And that's when a lot of these kids just, they can't, they can't do it. And they hate it. So I feel sorry, you know, for them, because they're used to be used to that quick reward. You know, you solve your problem. Maybe you take a day, maybe you take a week. Well, a thesis takes years of hitting walls and walls and levels. And so I think in that sense [...] Kids that have not felt frustrated and have not felt that impotence of my brain has been stretched this much. And I don't think I can give any more. I think it's a very sudden unexpected feeling for somebody who has been dealing with frustration day in and day out. It's like, yeah, I've given like sweat blood and tears to this thing. It's still not working, you know, but I think that's why it's been easier for me it's also easier for people that sometimes are bad students. They used to feeling not good.

\section{A.2}

And I think, it also, you know, it (mathematics) gives you a structure, for me it was about a structure, searching for something that would mold me as a person, as a human being and I think mathematics just has that. I know a lot of mathematicians are really disorganized, but there is order, you know, in that chaos, it grounds me to me it kind of, it always gives you a very fundamental reason, at least to me to go on, like you're pursuing a higher purpose, so, that's what happened for me was like a click.

\section{A.3}

[Fear] I think because math is hard everyone panics, and everyone was like if I don't grab on to the person next to me and study I'm going to die and everyone else was gonna die as well. So I think that fear kind of worked you know in the right way for us.

[Discomfort] I've had to grow really thick skin [...] you know women don't have an advantage. You don't get to tell it a little bit of you know, confidential information to your advisor that's going to make her feel better, you know, if you have a woman advisor or make her feel interesting or cool or you know it that does not happen. So, in that sense, yeah, I had an experience like that, and it was unpleasant.

[Feeling Useless] I'm glad that I wasn't a good student. I felt like I felt completely useless the entire time. So I'm used to the frustration. And I think that's why it's what it's helped me.

\section{A.4}

I like abstract algebra well enough to force myself to keep going. But I've always been more interested in the teaching side, and student's learning and that sort of thing. But the information I was given was that if I did my PhD in the education side, then I would be teaching courses to teachers. And then I wouldn't get to teach the math courses and what I really want to teach is the math courses. And then I found out recently, that solid portion, I don't remember the exact number of maybe like a quarter to a third of the education PhDs here get to go teach math courses at small schools. And one of my friends actually did that. He just graduated recently and is now teaching all math classes at a small college. That's like, well, wish I knew this sooner. But yeah, why not switch the dissertation to something I'm a lot more interested in.

\section{A.5}

Oh, when it comes to a PhD, I do feel that I need to prove, you know, to be better than the average to be more aware and more informed. Just because I know that some cards are stacked against me or will be in the future. So right now, that I'm going on to the job market, I'm trying to acquire all the information that I can on how to improve my CV or how to make the most of what I got going. And just while I was doing my PhD, I did feel that, it's less likely that you have, well. In my case, I have a specific, my advisor is not somebody that goes in, you know, hangs out with her students and [inaudible] it's just not, it's just not their nature. But I know some professors do that and they don't, for some coincidence, have girls among their students. I have to be better because I don't have the advantage of going to hang out and private time with my professor to prove to them that I'm cool, I'm bold and I'm a good hire, that they can trust me, that they can see me in a different light. [...] I don't get all these other advantages that you can see that these people get, you know, especially men, you know, women, there aren't that many. And the women there are in the department, they don't just go grab their girls and go for girls night. They probably should, but they don't. So there's that lack of camaraderie among women, they don't take pupils personally. Men do a lot, especially the younger professors.

\section{A.6}

I didn't like working on my own all day. The math was interesting. I was happy with that part of it. But just sitting there trying to figure stuff out on my own was not as fun. 